\title{
ANÁLISE DA INSERÇÃO DE CONTEÚDOS DE TEORIA QUÂNTICA NOS CURRÍCULOS DE FÍSICA DO ENSINO MÉDIO
}

\section{Quantum Theory contents insertion in High School curricula}

\author{
Teresa Lobato ${ }^{I}$ \\ Ileana María Greca
}

\begin{abstract}
Resumo: A inovação científica e tecnológica do século XX foi esmagadora. Contudo, a nossa experiência docente permite-nos afirmar que as aprendizagens na escola secundária estão longe de acompanhar a evolução que se verifica na sociedade atual. No entanto, já estão a ser incluídos alguns conteúdos de Física Moderna nos currículos oficiais de vários países, parecendo evidenciar uma preocupação em atualizar a preparação dos jovens para o mundo que os rodeia. Neste artigo relatamos um estudo que fizemos acerca dos currículos de Física de alguns países, sobretudo no que diz respeito à Teoria Quântica, a grande invenção do século XX, tentando identificar os conteúdos selecionados e a maneira como estes se integram nas orientações curriculares gerais.
\end{abstract}

Unitermos: Currículos (C), Teoria Quântica (TQ), Ensino Secundário (ES)

Abstract: In the $X X^{\text {th }}$ century, scientific and technological innovation has been overwhelming. Our teaching profession lead us to believe that studies in High Schools do not follow the evolution of ideas that characterizes our modern society. However, some contents of Modern Physics are already included in the official curricula of several countries, which seem to be worried about the improvement of today's youth training. In this paper we report a study made about Physics' curricula in several countries, emphasizing Quantum Theory issues, the biggest invention of the $X X^{\text {th }}$ century, trying to identify the selected subjects selected and the way they fit into general curricula orientations.

Keywords: Curricula, Quantum Theory, High School.

\section{Introdução}

Atualmente é consensual, entre físicos e professores de Física, a nível internacional, a necessidade de introduzir conteúdos de Física contemporânea nos currículos de Física do Ensino Secundário, (Jones 1991; Aubrecht, 1999; Gil e Solbes, 1993; Fischler e Lichfeldt, 1992; Lawrence, 1996; Pospiech, 1999 e 2000). Embora a descrição dos fenômenos não seja fácil para alunos tão jovens ou que pertençam a carreiras não científicas, a opção não deve ser a exclusão de tópicos tão importantes e populares (Hobson, 1995). É, pois, necessário que se estude como introduzir, no ES, os conceitos, leis e teorias da Física do Século XX, em particular a Teoria Quântica (TQ), que tem condicionado, fortemente, a investigação científica e tecnológica moderna e que, no século passado, revolucionou o pensamento humano. Conceitos bem estruturados na nossa cultura como o de localidade, trajetória ou determinismo tiveram de ser revistos. O próprio processo de fazer ciência, a relação entre teoria e experimentação, o papel do observador e do instrumento de observação adquiriram novas perspectivas.

Alguns rudimentos de TQ são já ensinados no ES ainda que, por vezes, na disciplina de Química. Desde os anos 80 do século passado, começaram a ser publicados alguns estudos sobre as concepções dos estudantes deste nível de ensino (Petri e Niedderer, 1998). Estudos

${ }^{1}$ Escola Secundária Fernando Lopes Graça - Av. Comandante Gilberto Duarte e Duarte, no 470 - 2775-200 Parede Portugal. Doutoranda do Programa Internacional de Doutoramento em "Enseñanza de las Ciencias" da Universidade de Burgos, Espanha, em convênio com a Universidade Federal do Rio Grande do Sul. E-mail: teresalobato@netcabo.pt

${ }^{2}$ Instituto de Física - UFRGS - Caixa Postal 15051 - 91501-970 Porto Alegre, RS, Brasil. E-mail: ileana@if.ufrgs.br 
feitos em Portugal (Sena, 1994; Sena e Caldeira, 1994; Caldeira, 1997), Espanha (Gil e Solbes, 1993), Inglaterra (Mashhadi, 1996) e Alemanha (Fischler e Lichtfeld, 1992; Petri e Niedderer, 1998), com alunos do ES, revelaram concepçôes acerca de fotôes, da estabilidade dos átomos, da dualidade e da mudança de paradigma. De uma maneira geral todos estes trabalhos mostram que, como indicam Sena e Caldeira (1994), a diversidade dos modelos conceituais propostos pelos alunos e a sua natureza, constituem indicadores de que o estado da compreensão da teoria permanece fértil num conjunto de concepçôes, manifestamente inconsistentes com a interpretação atual da Mecânica Quântica. Referências a concepçōes errôneas aparecem também em outros autores que têm estudado estes conceitos em alunos universitários (Styer, 1996; Johnston, Crawford e Fletcher, 1998; Aubrecht, Kassebaum, May e Smith, 1999; Ambrose, Shaffer, Steimber, e McDermott, 1999; Fletcher e Johnston, 1999; Hazidaki, Kalkanis e Stavrou, 2000). Segundo Styer, é freqüente detectar em estudantes, professores e textos concepções errôneas de função de onda, densidade de probabilidade, estado próprio de energia e o problema da medida, por exemplo. Estas concepções merecem atenção porque foram detectadas não só em alunos do ES mas também em estudantes do Superior, em professores e em textos, sendo provável que tenham tido origem nos cursos iniciais de TQ.

Resumindo, os resultados da literatura mostram que já foram estudadas as concepçôes de alunos do ES acerca da estabilidade do átomo, da dualidade onda-partícula, do princípio de incerteza, da quantização, de fotóes e electrōes (Greca, 2000, p. 32). Concluiu-se também que os vários itens analisados dificilmente foram entendidos pelos estudantes pesquisados, sendo estes, de diferentes níveis e modalidades de ensino e, ainda, de diferentes comunidades.

De uma maneira geral, todos reconhecem que, ainda que o assunto seja fascinante, é difícil devido às complexidades matemáticas e conceituais que envolve e, além disso, a literatura que existe disponível revela, sobretudo, que os alunos estão aprendendo conceitos errados. Cabe, então, perguntar se será mesmo desejável ensinar TQ nas escolas secundárias. Neste sentido, é interessante apontar que os resultados das pesquisas também parecem mostrar que, se as questôes fundamentais, os conceitos centrais da Mecânica Quântica, não são discutidos explicitamente nos cursos introdutórios, cursos mais avançados não conseguem ultrapassar as dificuldades iniciais (Greca, 2000). Assim, o problema parece residir na maneira como os conteúdos da TQ são aprendidos e não na altura em que são aprendidos. Aliás, os conceitos complexos e contra-intuitivos que envolve requerem muito tempo de reflexão, o que justificaria a sua introdução o mais cedo possível, de preferência no ES (Johnston, Crawford e Fletcher, 1998).

A necessidade da incorporação de conteúdos de Física Moderna não se tem limitado a discussões entre pesquisadores da área de ensino de Ciências. De fato, os currículos oficiais de diferentes países, cientes da importância da TQ na cultura tecnológica atual, já integraram esses conteúdos. Ainda que, o que efetivamente é estudado em sala de aula nem sempre coincida com o estipulado nos currículos, também é um fato que as orientaçōes dos mesmos influenciam as abordagens adotadas. Por isso consideramos interessante analisar a maneira como os conteúdos de TQ estão sendo oficialmente introduzidos no ES, como se articulam com outros conceitos mais clássicos e a relevância que lhes é dada no conjunto dos temas considerados suficientemente importantes para serem objeto de estudo no ES. As conclusôes que agora se relatam, fazem parte de uma investigação mais ampla, que tem por objetivo implementar a aprendizagem de conteúdos de TQ na disciplina de Física do ES português, onde só no próximo ano letivo (2005-2006), o tema começará a ser lecionado.

A pesquisa acerca dos currículos que aqui apresentamos foi feita, essencialmente, via Internet. Tendo Portugal como ponto de observação, procuraram-se os sítios oficiais dos governos de vários países (Espanha, França, Reino Unido, Dinamarca, Suécia, Canadá e Austrália), 
começando pelos que lhe estão mais próximos e neles, as determinações gerais que orientam os currículos dos cursos de Física do ES. Foram também analisados o currículo do Instituto Espanhol em Lisboa e diversas informaçóes prestadas por colegas de diferentes países, que responderam a um questionário que enviamos.

A análise de documentos tão vastos como os que são objeto deste estudo requer uma perspectiva teórica que a oriente. As noções adaptadas de currículo, instrução, aprendizagem e avaliação, estão em sintonia com a perspectiva de Mauritz Johnson. Johnson (1967), ao definir currículo como série estruturada de resultados de aprendizagem propostos, separa a função instrucional da curricular. Elaborar um currículo significa escolher e estruturar uma série de resultados propostos. A instrução está relacionada com a ação/interação desenvolvida por professores e alunos, a partir do currículo, e destinada a facilitar a aprendizagem desejada. Ao antecipar o que deve ser feito, o currículo guia a instrução mas não se confunde com ela. A seqüência das experiências de aprendizagem também é, segundo Johnson, influenciada pelo currículo, já que a relação entre os vários itens deve obedecer a uma estrutura hierárquica devidamente especificada.

A cultura humana, ensinável e disponível, é a fonte dos resultados de aprendizagem propostos num currículo. Assim, torna-se indispensável o estabelecimento de critérios de seleção (para escolher os conteúdos apropriados a determinadas finalidades) e estruturação (para decidir acerca da organização dos assuntos escolhidos), obviamente imbuídos de valores sociais e metas educacionais. A investigação que agora se relata procurou, nos documentos analisados, os conteúdos de TQ considerados relevantes para serem propostos como resultados de aprendizagem dos alunos do ES, no início deste novo milênio. E, como a planificação da instrução depende também da organização dos currículos, procuramos identificar, ainda, a respectiva estrutura. Antes de avançar é importante ressaltar que os países cujos currículos foram analisados possuem estruturas sociopolíticas consideravelmente diferentes, o que influencia a maneira como as orientaçôes curriculares são definidas e implementadas. Assim, na Austrália e Canadá o controle da educação não é feito nacionalmente mas a nível "estatal" (não nacional) e, nos outros países, existem orientaçóes nacionais regulamentadas por diferentes instâncias de poder: regionais, municipais, locais (http://www.inca.org.uk). Tentou-se, em todos os casos, identificar as normas gerais que guiam a construção do currículo do ES e neste, as orientações relativas à aprendizagem de TQ.

\section{Descrição de alguns currículos}

Inicialmente apresentaremos uma breve descrição das informações recolhidas em relação aos currículos dos diferentes países, destacando aquelas referidas a conteúdos de TQ. Posteriormente apresentaremos uma análise mais sistemática destes dados.

\section{Portugal}

Durante os anos letivos de 2003/2004, começou a ser implementada, neste país, uma nova reforma curricular para o ES. As principais finalidades enunciadas, para todas as disciplinas de ciência, são as que contribuam para a formação de uma cidadania democrática e que motivem os estudantes para o prosseguimento de carreiras científicas. A ciência é entendida como um meio de proporcionar a cada aluno um quadro de referências, de atitudes, de valores e de capacidades que o ajudem a crescer a nivel pessoal, social e profissional. O ensino da Física e da Química (que durante dois anos do ES se faz numa só disciplina) estrutura-se em torno de situaçôes-problema, recolhidas do cotidiano dos alunos, para a compreensão das quais se recorre à interdisciplinaridade, com vista a conciliar as análises parciais fomentadas pelos conhecimentos 
disciplinares. A abordagem Ciências, Tecnologia e Sociedade (CTS) é feita a partir de problemas familiares aos alunos, através dos quais se organizam estratégias de ensino e aprendizagem que incidirão nas vantagens de conhecer conteúdos da ciência e da tecnologia para melhor entender e controlar o ambiente. A TQ, ou rudimentos dela, aparece(m) só no último ano de escolaridade, o $12^{\circ}$, onde a Física já é disciplina autônoma. Durante este ano, os temas abordados são: Mecânica (35 aulas); Eletromagnetismo (23 aulas) e Física Moderna (20 aulas). Este último capítulo inclui conteúdos de Teoria da Relatividade (7 aulas) e TQ (13 aulas). A TQ é apresentada segundo uma perspectiva histórica que começa com a hipótese de Plank, passa pela contribuição de Einstein, pela relação de De Broglie e acaba no princípio de incerteza. Seguidamente estudam-se, também, rudimentos da estabilidade nuclear e da radioatividade.

\section{Espanha}

$\mathrm{Na}$ Espanha, a educação baseia-se numa concepção construtivista de ensino em que o aluno se converte no motor da sua aprendizagem. O currículo de Física é marcadamente CTS e tem como temas transversais a educação ambiental, educação para a saúde, educação do consumidor e educação não sexista. A TQ aparece no último ano do Ensino Secundário (2º de Bachillerato - Ciencias e Ingeniería) inserida num conjunto de temas genericamente designados por Física Moderna. Esta, que ocupa aproximadamente um terço do ano letivo (no Instituto Espanhol de Lisboa), é antecedida por outros conteúdos programáticos organizados em dois grandes blocos: Mecânica e Eletromagnetismo. Pretende-se que o estudo da Física, neste último ano de escolaridade secundária, que ocupa 4 horas letivas semanais, complemente os conhecimentos adquiridos em anos anteriores, através do estudo da teoria de gravitação universal, do movimento ondulatório, da ótica e da interação eletromagnética. A Física Moderna é introduzida através da apresentação de fenomenologia para a qual a Física Clássica apresenta explicações insuficientes, seguida do estudo dos novos conceitos para explicação dos fenômenos mencionados: postulados de relatividade especial; radiação térmica; catástrofe do ultravioleta; efeito fotoelétrico; experiência de Hertz; espectros atômicos; hipótese de Planck; quantização de energia; hipótese de De Broglie; dualidade onda-corpúsculo; princípio de incerteza de Heisenberg; determinismo, probabilidade e domínio de validade da Física Clássica. Finalmente estudam-se, como aplicaçōes da Física Moderna, os seguintes temas: física nuclear; radioatividade; interação nuclear forte; fusão e fissão, suas aplicações e riscos e introdução ao estudo das partículas elementares.

\section{França}

O programa de Física do último ano do ES francês (Terminal S), baseia-se na compreensão da evolução dos sistemas, em termos quantitativos, estudada tanto teórica como experimentalmente. Segundo as orientações deste currículo, do ponto de vista experimental, observar uma evolução é medir taxas de variação de certas grandezas físicas. Quer se trate da propagação de uma perturbação num meio, do estabelecimento de uma corrente num circuito elétrico, do movimento de um satélite ou da desintegração de um núcleo radioativo, são sempre as taxas de variaçãao associadas que são relevantes em termos de estudo. Do ponto de vista teórico, a taxa de variação instantânea representa-se por uma derivada e, estudando os parâmetros que influenciam a derivada de uma grandeza física, estabelece-se uma equação diferencial cuja resolução permite antecipar a evolução real do sistema. A matemática é, portanto, encarada como parte constituinte da Física e não como mera ferramenta de trabalho. A variedade dos temas abordados durante o ano tem como fio condutor a evolução temporal dos sistemas fisicos, o que permite enquadrar os diferentes assuntos abordados e fixar os respectivos limites. A execução de um método 
numérico interativo permite ancorar as idéias de determinismo e causalidade. A TQ aparece no segmento do estudo dos sistemas mecânicos. Algumas constataçóes simples (a identidade de sistemas nucleares ou atômicos comparada com a variedade de sistemas planetários, o tamanho dos átomos) sugerem que a dinâmica que rege os sistemas nucleares, atômicos e moleculares deve ser diferente da dinâmica clássica. Segundo expresso no currículo, não se pretende avançar na explicação das questôes levantadas que, provisoriamente, ficarão sem resposta, mas criar uma abertura para o mundo quântico introduzido pela constante de Planck.

\section{Reino Unido (Inglaterra e Pais de Gales)}

O novo currículo de Advancing Physics, no Reino Unido, está organizado de forma a atrair mais e melhores estudantes para a Física. Embora mantendo a identidade própria, pretende-se que os conteúdos sejam atrativos e evidenciem o quadro completo das potencialidades que a disciplina pode oferecer, isto é, não só satisfação intelectual e pessoal, como também a possibilidade de carreiras profissionais produtivas. Transparece a necessidade de adaptação a um mundo em transformação onde os dispositivos eletrônicos, as imagens digitais e as comunicaçôes, cada vez mais rápidas, estão forçando novos estilos de vida. Assim, o interesse que os estudantes manifestam pela tecnologia atual parece ser o ponto de partida para a aprendizagem de temas antigos. Os assuntos estudados não excluem tópicos tradicionais mas se apresentam de maneira diferente. O curso do primeiro ano (Advance Subsidiary Course - AS), organiza-se em torno de duas idéias-chave: Física em Ação e Compreendendo Processos. A primeira (que inclui os temas Communication e Designer Materials) pretende orientar os conhecimentos, anteriormente adquiridos, para os estudos no curso AS e foca a utilização da Física em diferentes circunstâncias; a segunda (que inclui os temas Waves and Quantum Behaviour e Space and Time) progride em novas maneiras de pensar e foca a Física guiada pela curiosidade. O curso do $2^{\circ}$ ano (Advanced Level Course - A2) organiza-se em torno das idéias-chave Ascensão e Queda do Universo Mecanicista e Imagens de Campo e Partículas. A primeira (que inclui os temas Models and Rules e Matter in Extremes) pretende um desenvolvimento gradual do pensamento matemático e foca a maneira como a Física modifica as nossas vidas e nossa maneira de pensar; a segunda (que inclui os temas Campos, Partículas Fundamentais da Matéria e Avanços em Física) pretende o desenvolvimento de idéias fundamentais e foca uma variedade de pontos de vista que vão de aplicaçôes da Física a assuntos de interesse social.

\section{Dinamarca}

A grande finalidade da instrução neste país em relação à Física é que os alunos percebam assuntos centrais de Física Clássica e Moderna, especificados em um núcleo de programa, como meio de entender o mundo que nos rodeia, as maneiras científicas de pensar, o método científico e a relação entre a Física e o desenvolvimento tecnológico, cultural e social. Assim, são definidos dois cursos com diferentes níveis de exigência: o nível obrigatório (B-level) e o superior (A-level). No que diz respeito aos temas que, para efeitos deste trabalho interessa considerar, são mencionados como fazendo parte do currículo essencial: a composição dos átomos e dos núcleos atômicos, a emissão e absorção de radiação pelos fotões, decaimento radioativo, reações nucleares e radiações ionizantes ( $B$-level); equivalência massa-energia, reações nucleares e processos no interior das estrelas, tratamento das leis de conservação do impulso, energia e carga (A-level).

\section{Suécia}

Os cursos de Física, neste país, pretendem proporcionar conhecimento e desenvolver capacidades, necessários tanto a estudos superiores de ciências naturais e tecnologias, como a estudos e atividades de outras áreas. Pretende-se que os alunos experimentem a satisfação e o 
estímulo intelectual que advém de se conseguir compreender e explicar os fenômenos do mundo natural. Pretende-se, também, contribuir para que os alunos adquiram conhecimentos que lhes permitam entender e intervir publicamente em questóes relacionadas com as ciências naturais. Tal implica a análise e o desenvolvimento de pontos de vista importantes, quer a nível individual, quer a nível social, de que são exemplo os que dizem respeito a assuntos energéticos, ambientais e éticos. A área de estudo da Física estende-se do muito grande ao muito pequeno, do desenvolvimento do universo às propriedades das partículas subatômicas. A energia aparece como conceito que faz a ligação entre assuntos anteriormente tidos como diferentes. Num sentido lato a Física atual trata da matéria, da radiação e de diferentes tipos de interação. Tanto em Física como em outras ciências naturais o currículo deste país parte do pressuposto de que o conhecimento é construído através da interação entre observações experimentais e modelos teóricos. Assim, a experimentação deve desempenhar papel importante no ensino da Física. Através do trabalho laboratorial os alunos treinariam as suas capacidades em planificar experiências, usar instrumentos de medida e analisar dados. Além disto, é propiciada a incorporação de técnicas computacionais, em determinados modelos, para a discussão dos diferentes fatores que influenciam os resultados experimentais.

\section{Canadá (Ontário)}

O currículo de educação científica da província de Ontário baseia-se na crença de que o impacto que a ciência teve na vida do século XX, se continuará a fazer sentir durante o século XXI. Assim, a grande finalidade proposta é a literacia científica que se define como sendo a posse de conhecimentos científicos, competências e hábitos de raciocínio necessários para prosperar na sociedade com base científica do século XXI. Todo o currículo de educação científica, no ES, se constrói em torno de três pilares que refletem uma tríade essencial: conhecimento, competências e a habilidade de relacionar a ciência à tecnologia, à sociedade e ao ambiente. Analisando, com algum detalhe, o programa de Física do último ano (Grade 12, University Preparation), verifica-se que este curso pretende que os estudantes aprofundem a sua compreensão de conceitos e teorias da Física. Nesta perspectiva estudarão: as leis da dinâmica e das transformaçôes de energia; campos gravíticos, magnéticos e elétricos; radiação eletromagnética e a interface entre energia e matéria. É com o estudo deste último tema que os alunos devem aprender a entender os conceitos elementares da teoria especial de relatividade de Einstein e o desenvolvimento dos modelos da matéria baseados nas mecânicas clássica e quântica inicial. É também através da interface entre matéria e energia que se devem implementar experiências como meio de explorar idéias científicas abstratas e descrever como a introdução de modelos e teorias podem influenciar e modificar o pensamento científico que origina novas tecnologias.

\section{Austrália}

No currículo australiano analisado, a Física define-se como uma área de conhecimento que está relacionada com a compreensão da estrutura da natureza e com a explicação de fenômenos naturais. O estudo da Física amplia o nosso conhecimento do mundo e encoraja o ceticismo saudável, a procura de soluções para problemas e o desejo, tanto da procura da causa das coisas, como da explicação racional dos eventos. Os processos, as atitudes e os valores da Física são considerados meios poderosos para gerar conhecimento, o que implica que os cursos desta área sejam elaborados no pressuposto de que o seu conteúdo é importante para todos. Com estes cursos pretende-se que os estudantes desenvolvam competências para efetuar trabalho de investigação com criatividade, responsabilidade, confiança e competência. Os cursos de Física são estruturados em torno de conteúdos, conceitos e processos-chave. Pare efeitos 
deste trabalho interessa-nos considerar os conteúdos-chave física atómica e física nuclear que são desenvolvidos em torno dos seguintes conceitos-chave: espectros; partículas subatômicas; Física Quântica; dualidade onda-partícula; dispersão; partículas subatômicas; fissão, fusão e forças nucleares.

\section{Análise dos currículos}

Sociedades que diferem entre si por aquilo que, positiva ou negativamente, valorizam, têm conceitos diferentes do que deve ou não ser ensinado na escola. Moreira e Axt, (1987), elaboraram um quadro síntese onde se faz a comparação entre várias concepções curriculares, identificadas por Eisner e Vallence que, por se considerar importante na análise que este trabalho pretende fazer, se reproduz na figura 1.

\begin{tabular}{|c|c|c|}
\hline $\begin{array}{c}\text { Concepção } \\
\text { Curricular }\end{array}$ & $\begin{array}{c}\text { Processos } \\
\text { Enfatizados }\end{array}$ & $\begin{array}{c}\text { Importância do } \\
\text { Conteúdo }\end{array}$ \\
\hline Desenvolvimento dos processos cognitivos & Cognitivos & $\begin{array}{c}\text { Não é importante; raramente se refere ao } \\
\text { conteúdo. }\end{array}$ \\
\hline Tecnologia & Tecnológicos & $\begin{array}{c}\text { Não é questionado; o importante é trans- } \\
\text { miti-lo eficientemente. }\end{array}$ \\
\hline Auto-realização & Pessoais & $\begin{array}{c}\text { O conteúdo, como experiência auto-real- } \\
\text { izadora, é fundamental. }\end{array}$ \\
\hline Reconstrução social & Sociais & $\begin{array}{c}\text { O conteúdo é importante do ponto de } \\
\text { vista social. }\end{array}$ \\
\hline Racionalismo acadêmico & Científicos & $\begin{array}{c}\text { O conteúdo das disciplinas clássicas é o } \\
\text { mais importante. }\end{array}$ \\
\hline
\end{tabular}

Figura 1. Quadro comparativo das concepções curriculares identificadas por Eisner e Vallence, em termos da importância do conteúdo (Moreira e Axt, 1987, p. 8).

Como os currículos que queremos analisar respeitam o ensino da Física, uma outra categorização feita por Roberts, também citada por Moreira e Axt (op. cit.), vai ser útil para completar este estudo. Esta categorização diz respeito aos currículos de ciências e parte da definição de ênfase curricular como um conjunto coerente de mensagens sobre ciência comunicadas, explícita ou implicitamente, ao estudante (Roberts, apud. Moreira e Axt, 1987, p. 9). Ou seja, o currículo pode incluir mensagens que não se limitam à aprendizagem de leis e teorias referentes ao conteúdo científico propriamente dito. As ênfases curriculares identificadas por Roberts, em número de sete, estão sintetizadas no quadro da figura 2. 


\begin{tabular}{|c|c|c|}
\hline Enfase curricular & Processo valorizado & Mensagem sobre ciência \\
\hline Ciência do cotidiano & $\begin{array}{l}\text { Entendimento individual e coletivo de } \\
\text { processos científicos como meio de lidar } \\
\text { com problemas sociais e coletivos }\end{array}$ & $\begin{array}{l}\text { A ciência é um importante meio para } \\
\text { entender e controlar o ambiente }\end{array}$ \\
\hline Estrutura da ciência & $\begin{array}{c}\text { Discussão de assuntos como interação } \\
\text { entre experiência e teoria e adequação de } \\
\text { determinado modelo a determinado } \\
\text { fenômeno }\end{array}$ & $\begin{array}{c}\text { Funcionamento intelectual da ciência ao } \\
\text { crescer e desenvolver-se }\end{array}$ \\
\hline Ciência, Tecnologia e Sociedade, CTS & $\begin{array}{c}\text { Distinção entre ciência e tecnologia, } \\
\text { relaçôes entre uma e outra e respectivas } \\
\text { implicações na sociedade }\end{array}$ & $\begin{array}{c}\text { A ciência e a tecnologia influenciam a } \\
\text { sociedade; os acontecimentos sociais } \\
\text { repercutem-se nelas }\end{array}$ \\
\hline Habilidades científicas & $\begin{array}{l}\text { Desenvolvimento de habilidades } \\
\text { necessárias às atividades científicas }\end{array}$ & $\begin{array}{l}\text { O uso hábil dos meios científicos leva a um } \\
\text { fim correto }\end{array}$ \\
\hline Explicações corretas & $\begin{array}{c}\text { Legitimação das explicações científicas } \\
\text { através da autoridade de alguns } \\
\text { cientistas }\end{array}$ & $\begin{array}{l}\text { As idéias aceitas pela comunidade são boas, } \\
\text { as outras não }\end{array}$ \\
\hline Indivíduo como explicador & $\begin{array}{c}\text { A história da ciência é usada como meio } \\
\text { para ensinar como se faz ciência }\end{array}$ & $\begin{array}{l}\text { A humanidade da ciência é a do estudante } \\
\text { que é encarado como explicador de fatos }\end{array}$ \\
\hline Fundamentação sólida & $\begin{array}{c}\text { O que se aprende vai ser usado na etapa } \\
\text { seguinte }\end{array}$ & $\begin{array}{c}\text { O que se aprende está inserido numa } \\
\text { estrutura planejada }\end{array}$ \\
\hline
\end{tabular}

Figura 2. Quadro comparativo das ênfases curriculares identificadas por Roberts.

Embora não tendo sido possível observar os materiais didáticos que estes currículos terão originado, o respectivo estudo permite tirar algumas conclusões acerca da maneira como se pretende que os alunos do ES estudem os conteúdos de TQ, nos países envolvidos no estudo. Além disto, as respostas que colegas de diferentes países europeus deram em questionários que propusemos, via Internet, permitiram-nos obter dados adicionais relacionados, essencialmente, com a prática pedagógica.

De acordo com os critérios definidos anteriormente e tendo em conta que as classificaçôes de ênfases curriculares ou de concepçôes curriculares não são mutuamente exclusivas ou de caráter inequívoco, podemos, ainda assim, tirar algumas conclusōes.

No novo currículo português os temas de Física e Química propostos parecem estar organizados não conforme o seu valor intrínseco, mas como meio de proporcionar um quadro de referências, de atitudes, de valores e de capacidades que ajudem os alunos a crescer a nivel pessoal, social e profissional. Como já foi referido a TQ aparece só no fim do curso secundário e de acordo com uma perspectiva histórica, convencional, o que, aliás, contrasta com as opções tomadas para os temas tratados na disciplina bienal de Física e Química que antecede a disciplina de Física.

No currículo da Espanha também perpassam preocupaçōes de ordem de reconstrução social, sobretudo ligadas a questões do ambiente, da saúde, do consumidor e da educação não sexista. No entanto, a organização curricular é feita em torno da racionalidade científica na medida em que é a organização lógica dos conteúdos de Mecânica, Eletromagnetismo e Física Moderna que comanda a organização curricular. Os conteúdos são mencionados em espiral, de acordo com a faixa etária dos alunos e de maneira que estes possam adquirir um conjunto completo e coerente do edifício da ciência. A TQ aparece associada à mudança de paradigma, o que é perfeitamente coerente com a estrutura geral adotada: a certa altura a construção do edifício da Física levou um "rombo" que teve de ser tratado como tal. A seqüência dos assuntos estudados em Física Moderna segue a lógica tradicional, de acordo com a evolução histórica.

O currículo da França, tanto quanto nos foi dado observar, é bastante diferente dos anteriores. Não se preocupa com a intervenção social ou com a ciência do cotidiano. Parece 
desenvolver-se, exclusivamente, em torno de uma certa maneira de encarar a construção do edifício científico: a evolução temporal dos sistemas físicos, em que a matemática é encarada como parte integrante do sistema. Quanto à TQ pouco nos foi dado saber. Contrariamente às explicitações feitas acerca de outros temas de Física, no caso da TQ apenas se menciona que é introduzida através da constante de Planck. Seria interessante, no entanto, saber como a estratégia geral do currículo se aplica também aos problemas quânticos.

O currículo do Reino Unido é organizado em torno de temas que parecem ter como objetivo atrair jovens para o estudo da Física. Estes temas, nada convencionais, partem de assuntos de Física mais recentes para uma outra Física que, sendo atual, foi construída em tempos mais remotos. A TQ aparece logo no início do programa, antes mesmo da Mecânica, sem qualquer ênfase especial e é retomada, posteriormente, numa perspectiva de aprofundar conhecimentos anteriores. Não há, neste caso, qualquer referência a mudança de paradigmas. A introdução dos diagramas de Feynman como objeto de estudo, em detrimento da opção tradicional usada anteriormente, é uma inovação à maneira de introduzir assuntos quânticos aos alunos mais jovens. A atualidade dos temas escolhidos parece ter sido o critério de seleção que orientou a organização do currículo (aparentemente) para a mostrar a beleza e utilidade da Física, de forma coerente com o objetivo geral do currículo de Física.

Os currículos da Dinamarca, Suécia, Canadá e Austrália, embora com algumas características diferentes, implicam sempre vertentes em que a reconstrução social é uma preocupação recorrente que, no entanto, pode estar mais dirigida para assuntos ambientais ou de realização pessoal/social. A TQ, nestes casos, não é associada a mudanças de paradigma, mas incluída no edifício completo de ciência que se pretende transmitir. Geralmente a TQ é abordada em dois momentos do currículo com dificuldade crescente. Os temas abordados são sempre coerentes com a orientação curricular geral.

Embora não tendo tido acesso aos currículos oficias do ensino secundário da Finlândia e Itália, através de professores que responderam a questionários que propusemos, via Internet, sabemos que, na Finlândia, a TQ é introduzida através de uma aproximação experimental (Experimental approach where phenomen comes first and theory after-Abordagem experimental onde os fenômenos precedem a teoria) e, na Itália, de maneira tradicional (começa com o problema da radiação do corpo negro e efeito fotoelétrico, passa pelos vários modelos atômicos, e, o "estranho comportamento quântico" é discutido através do princípio de incerteza e da dualidade onda-corpúsculo).

Quanto à maneira como a TQ é introduzida notam-se algumas diferenças. Em Portugal, Espanha e França a TQ aparece no final do curso e ligada à mudança de paradigma. Nos dois primeiros países, agora referidos, é introduzida de forma histórica e, no terceiro, de acordo com a lógica geral do currículo, isto é, de acordo com a dinâmica dos sistemas. Nos demais países a TQ está ligada ao estudo da física das partículas e faz-se em dois tempos: no primeiro ano, relacionada com a constituição da matéria e no segundo ano, com as reaçôes nucleares. De destacar o caso do Reino Unido, onde a física das partículas aparece logo no início do curso, antes da mecânica, por exemplo, e com referências a diagramas de Feynman.

Em relação aos assuntos abordados, dualidade, níveis de energia, experiência da dupla fenda, efeito fotoelétrico e princípio de incerteza são mencionados em todos os currículos. O princípio de sobreposição de estados, o modelo da partícula na caixa e o efeito de túnel só são mencionados em um projeto piloto (experimental), efetuado na Holanda, não integrado no currículo normal das escolas (http://malcol.org/eps_seminar/Paper/bo6.html e http://teachers.web.cern.ch/teachers/materials/syllabus.htm). Neste último, é de referir também, à alusão à interface microscópico/macroscópico como meta explícita de aprendizagem. A 
equação de Schrödinger só aparece mencionada neste projeto e, mesmo assim, como assunto opcional. Portanto, contrariamente ao que acontece no caso de conteúdos da Física Clássica, a TQ, normalmente, não é apresentada a partir de respectiva equação do movimento, possivelmente considerada muito complexa para os estudantes de ES. Apesar da complexidade, cabe perguntar se esta forma de apresentar explicaçōes isoladas de fenômenos que pertencem ao âmbito da TQ será a melhor forma de contribuir para que os alunos a entendam como um conjunto completo e coerente de modelos científicos.

De acordo com as orientaçôes curriculares gerais, todos os currículos incluem aplicações, tanto teóricas como tecnológicas, da TQ. Assim, a ligação à tecnologia, às necessidades sociais e ambientais, ao cotidiano e ao que se julga ser de interesse dos jovens é preocupação recorrente quando se referem aos conteúdos de TQ recomendados.

No quadro da figura 3 faz-se a síntese possível dos dados recolhidos com a análise efetuada aos currículos. Neste, os lugares reservados a itens acerca dos quais não conseguimos informação relevante são deixados em branco. Note-se que em vários dos documentos analisados não conseguimos inferir o tempo relativo destinado a assuntos de TQ. No entanto, é de referir que esta é parte integrante de todos os currículos observados, ainda que com estratégias de inserção diferentes.

\begin{tabular}{|c|c|c|c|c|c|}
\hline País & $\begin{array}{c}\text { Estratégias } \\
\text { introdução de } \\
\text { TQ }\end{array}$ & $\begin{array}{c}\text { Altura de } \\
\text { introdução da } \\
\text { TO }\end{array}$ & $\begin{array}{l}\text { Tempo } \\
\text { previsto }\end{array}$ & $\begin{array}{c}\text { Temas } \\
\text { abordados }\end{array}$ & $\begin{array}{c}\text { Aplicaçōes TQ } \\
\text { mencionadas }\end{array}$ \\
\hline Portugal & $\begin{array}{c}\text { Tradicional; mudança de } \\
\text { paradigma }\end{array}$ & Fim do ES & $\begin{array}{c}\text { 17\% do currículo de } \\
\text { último ano }\end{array}$ & $\begin{array}{l}\text { Quantização; dualidade; } \\
\text { princípio de incerteza }\end{array}$ & $\begin{array}{l}\text { Microscópio eletrônico; } \\
\text { radioatividade; fusão e fis- } \\
\text { são nucleares }\end{array}$ \\
\hline Espanha & $\begin{array}{c}\text { Tradicional; mudança de } \\
\text { paradigma }\end{array}$ & Fim do ES & $\begin{array}{c}30 \% \text { do currículo de } \\
\text { último ano }\end{array}$ & $\begin{array}{l}\text { Quantização; dualidade; } \\
\text { princípio de incerteza; } \\
\text { determinismo }\end{array}$ & $\begin{array}{l}\text { Física nuclear; radioativi- } \\
\text { dade; fusão e fissão; física } \\
\text { de partículas }\end{array}$ \\
\hline França & Mudança de paradigma & Fim do ES & & $\begin{array}{l}\text { Quantização; constante de } \\
\text { Planck }\end{array}$ & \\
\hline Reino Unido & $\begin{array}{c}\text { Física de partículas; } \\
\text { QED }\end{array}$ & $\begin{array}{c}\text { Início ES e retomado no } \\
\text { fim }\end{array}$ & $\begin{array}{l}28 \% \text { do currículo de } 2 \\
\text { anos }\end{array}$ & $\begin{array}{l}\text { Interferência; difração; } \\
\text { dualidade; quantizaçãoo }\end{array}$ & $\begin{array}{l}\text { Efeito fotoelétrico; } \\
\text { microscópios eletrônicos }\end{array}$ \\
\hline Dinamarca & & $1^{\circ}$ ano $+2^{\circ}$ ano & & Física atômica e nuclear & Astrofísica \\
\hline Suécia & & $1^{\circ}$ ano $+2^{\circ}$ ano & & Física atômica e nuclear & Astrofísica; estado sólido \\
\hline Canadá & & Último ano (pelo menos) & & $\begin{array}{c}\text { Física de partículas; } \\
\text { quantização }\end{array}$ & $\begin{array}{c}\text { Contribuiçôes canadenses à } \\
\text { Física Moderna }\end{array}$ \\
\hline Austrália & & & & Física atômica e nuclear & $\begin{array}{l}\text { Dualidade; dispersão; } \\
\text { espectros }\end{array}$ \\
\hline Itália & Tradicional & Fim do curso secundário & & $\begin{array}{l}\text { Constante de Planck; ef. } \\
\text { fotoelétrico; modelos } \\
\text { atômicos; dualidade; } \\
\text { princípio de incerteza }\end{array}$ & \\
\hline Finlândia & Tradicional/experimental & & & $\begin{array}{c}\text { Quantização, física de } \\
\text { partículas }\end{array}$ & Efeito fotoelétrico \\
\hline
\end{tabular}

Figura 3: Síntese das informações recolhidas na análise de currículos. 
Análise da inserção de conteúdos de Teoria Quântica...

\section{Conclusões}

A abordagem tradicional (que utiliza a via histórica) encontra-se nos currículos de Portugal, Espanha, Itália e Finlândia. Introduz a TQ através da hipótese de Planck e efeito fotoelétrico, seguidos da discussão da "peculiaridade do comportamento quântico" através do princípio da incerteza e da dualidade onda-partícula. De uma maneira geral, à enumeraçāo inicial das noçôes da TQ seguem referências às respectivas aplicaçôes práticas, bem como aos riscos que lhes são inerentes. Foi também possível detectarmos que esta abordagem pode originar instruçōes diferentes, conforme se acentue a vertente filosófica ou a vertente experimental. Pelo menos é o que se depreende do questionário respondido pelo colega da Finlândia quando declara que no seu país a abordagem é histórica e experimental, para de imediato acrescentar que acentua o caráter experimental, em detrimento do filosófico, através das frases: aproximação experimental, onde os fenômenos aparecem primeiro e a teoria a seguir; as interpretaçôes filosóficas podem tornar-se dificeis; é dificil entender o que não se pode ver. Uma mesma descrição curricular pode originar instruçôes com características diferentes.

Esta abordagem tradicional, quer a mudança de paradigma seja ou não referida como instrumento de aprendizagem, está sempre associada ao final dos cursos de Física. Parece estar relacionada com uma concepção cronológica do ensino da Física que começa na Mecânica, passa pelo Eletromagnetismo e acaba no Física Moderna (Relatividade e TQ).

É interessante destacar que, nos demais países analisados, esta abordagem tem sido deixada de lado (o que não acontece, por exemplo, nos currículos de Ensino Superior onde são apresentados conteúdos de TQ). Assim, a introdução da TQ através da proposta de Feynman, no livro QED, escolhida no Reino Unido, veio substituir a abordagem tradicional que vigorava neste país (Jones, 1991; Fischler \& Lichtfeldt, 1992; Ireson, 2000) até muito recentemente, e que foi considerada responsável pelo aparecimento de conceitos errôneos. Mais uma vez quebrando a tradição, neste caso a TQ começa a ser estudada logo no início do ciclo de estudos do secundário, para ser posteriormente retomada, numa perspectiva de aprofundar os conhecimentos adquiridos. A estratégia de introdução já não está relacionada com a cronologia dos acontecimentos, mas com a lógica dos temas escolhidos para organizar o currículo.

Nos currículos da Dinamarca, Suécia, Canadá e Austrália, os conteúdos de TQ têm um tipo de tratamento idêntico: na maneira como estão integrados, na relação que se estabelece entre experimentação e modelação teórica e nas conseqüências para a sociedade e meio ambiente. Esta abordagem não tradicional da introdução da TQ faz-se sempre em duas ocasiōes distintas de aprendizagem, está associada à Física das Partículas e não acentua a mudança de paradigma. Aparentemente estas abordagens não deixam a TQ para o "final" do ES, como último assunto a abordar... se der tempo. Pelo contrário, parece existir uma preocupação em que estes conteúdos sejam vistos como parte integrante de todo o edifício da Física que deve ser ensinado no ES. Além disto, a integração destes assuntos em duas oportunidades diferentes, com graus de dificuldade crescente, possivelmente destina-se a que os estudantes consigam uma melhor compreensão dos mesmos.

De todo modo, os conteúdos escolhidos e as formas como se propõem serem tratados, ainda requerem muita pesquisa para saber se, de fato, conseguem contribuir para que os estudantes entendam melhor o mundo microscópico do que com a abordagem dita tradicional. São também necessárias pesquisas para saber como é que os professores ensinam estes conteúdos em sala de aula. A este respeito é interessante destacar que, durante a presente investigação, encontramos somente dois trabalhos exclusivamente dedicados à formação de docentes, os quais indicam que os conceitos quânticos dos professores em início de carreira, são semelhantes aos 
dos outros estudantes já referidos neste trabalho. Um, de um grupo de investigadores da Universidade de Atenas, considera que as concepçōes errôneas dos futuros professores funcionam como obstáculos espistemológicos à aquisição de conhecimentos da Física Moderna (Hadzidaki, Kalkanis and Sravrou, 2000), e, por isso, organizou cursos de formação baseados na discussão dos dois grandes paradigmas da Física. Um outro grupo de investigadores, da Universidade de Milão, para resolver o mesmo problema, implementou uma proposta dirigida a professores estagiários, que envolve um curso a ser ministrado em salas de aula do ES, cuja avaliação é, posteriormente, englobada na formação dos professores em formação (Giliberti, Cazzaniga e Lanz, 2002).

Tendo concluído que os conteúdos de TQ, de fato, já fazem parte de programas oficiais do ES, é necessário passar à questão seguinte: qual será a melhor maneira de os abordar? Não se pode ignorar que as tentativas de ensinar TQ a cursos introdutórios, tanto do ES como do Superior, têm contribuído para o aparecimento de conceitos errôneos que só podem ter origem na instrução, já que não há "senso comum" ou "teorias alternativas" que os expliquem. Assim, parece-nos que as próximas questôes de investigação devem estar relacionadas com a melhor maneira de ensinar os primeiros conceitos de TQ, especialmente no ES, o que certamente contribuirá para que, posteriormente, no Ensino Superior, os alunos detenham conceitos mais de acordo com a perspectiva científica. Além disso, convém não esquecer que os resultados das pesquisas feitas para avaliar as concepçôes quânticas, tanto de professores como de estudantes do Ensino Superior, indicam que não se pode ignorar a necessidade de organizar trabalhos de investigação com o objetivo de melhorar a preparação científica de professores que venham a dedicar-se ao ensino da TQ.

\section{Bibliografia}

AMBROSE, B. S. et al. An investigation of student understanding of single-slit diffraction and double-slit interference. American Journal of Physics, Woodbury, v. 67, n. 2, p. 146-155, 1999.

AUBRECHT, G. J. et al. Introductory students' ideas about quantization and photon. Announcer, College Park, v. 29, n. 2, p. 102, 1999.

CALDEIRA, H. Física moderna no secundário? In: ENCUENTRO IBÉRICO PARA LA ENSEÑANZA DE LA FÍSICA, 7, 1997, Las Palmas de Gran Canaria. Resúmenes de las Comunicaciones. Las Palmas de Gran Canaria: [s.n.], 1997.

FISCHLER, H.; LICHTFELDT, M. Modern physics and students' conceptions. International Journal of Science Education, Londres, v. 14, n. 2, p. 181-190, 1992.

FLETCHER, H.; JOHNSTON, I. Quantum mechanics: exploring conceptual change. In: ANNUAL MEETING NATIONAL ASSOCIATION FOR RESEARCH IN SCIENCE TEACHING, 1999, Boston. Paper... Boston: [s.n.], 1999.

GILIBERTI, M.; CAZZANIGA, L.; LANZ, L. QUANTA-MI. A modern teaching for modern physics in pre-service teachers training. In: GIREP Conference, 2002, Lund. Lund: [s.n.], 2002.

GIL, D.; SOLBES, J. The introduction of modern physics: overcoming a deformed vision of science. International Journal of Science Education, Londres, v. 15, n. 3, p. 255-260, 1993. 
GRECA, I. M. Construindo significados em mecânica quântica: resultados de uma proposta didática aplicada a estudantes de física geral. 2000. Tese (Doutorado em Física) - Universidade Federal do Rio Grande do Sul, Porto Alegre, 2000.

HADZIDAKI, P.; KALKANIS, G.; STAVROU, D. Quantum mechanics: a systemic component of the modern physics paradigm. Physics Education, London, v. 35, n. 6, p. 386-392, 2000.

HOBSON, A. Physics: concepts and connections. Nova Jersey: Prentice Hall, 1995.

IRESON, G. The quantum understanding of pre-university physics students. Physics Education, London, v. 35, n. 1, p. 15-21, 2000.

JOHNSON, M. Definitions and models in curriculum theory. Educational Theory, Urbana, v. 17, n. 2, p. 127-140, 1967.

JOHNSTON, D.; CRAWFORD, K.; FLETCHER, P. R. Student difficulties in learning quantum mechanics. International Journal of Science Education, London, v. 20, n. 4, p. 427-446, 1998.

JONES, D. G. C. Teaching modern physics - misconceptions of the photon that can damage understanding. Physics Education, London, v. 26, p. 93-98, 1991.

LAWRENCE, I. Quantum physics in school. Physics Education, London, v. 31, n. 5, p. 278-276, 1996.

MASHHADI, A. Students conceptions of quantum physics. In: WELFORD, G. et al. (Ed.).

Research in Science Education in Europe. London: The Falmer Press, 1996. p. 254-265.

MOREIRA, M. A.; AXT, R. Ênfases curriculares e ensino das ciências. Ciência e Cultura, São Paulo, v. 39, n. 3, p. 250-258, 1987.

PETRI, J.; NIEDDERER, H. A learning pathway in high school level quantum atomic physics.

International Journal of Science Education, London, v. 20, n. 9, p. 1075-1088, 1998.

POSPIECH, G. Teaching the EPR paradox at high school? Physics Education, London, v. 34, n. 5, p. 311-316, 1999.

POSPIECH, G. Uncertainty and complementarily: the heart of quantum physics. Physics Education, London, v. 35, n. 6, p. 393-399, 2000.

SENA, J. Um estudo sobre concepções e estratégias de ensino em mecânica quântica. 1994. Tese (Mestrado em Ensino da Física e da Química) - Universidade de Coimbra, Coimbra, 1994.

SENA, J.; CALDEIRA, M. H. Dualidade onda partícula setenta anos depois. In: ENCONTRO IBÉRICO PARA O ENSINO DA FÍSICA, 4, 1994. Livro de Resumos. Lisboa: Didáctica, 1994.

STYER, D.F. Common misconceptions regarding quantum mechanics. American Journal of Physics, New York, v. 64, n. 1, p. 31-34, 1996. 


\section{Teresa Lobato e Ileana María Greca}

\section{Endereços eletrônicos}

http://www.eurydice.org

http://averroes.cec.junta-andalucia.es/ies_gaviota/fisiqui/programacion/node38.html

http://teachers.web.cern.ch/teachers/materials/syllabus.htm

http://advancingphysics.iop.org/products/aims.html

http://www.malcol.org/eps_seminar/Papers/b02.html

http://www.qca.org.uk/nq/subjects/physics.asp

www.aqa.org.yk/qual/pdf/AQA6451WSP.pdf

http://us.uvm.dk/gymnasie/almen/lov/bek/supplement14.html

http://www.edu.gov.on.ca

http://www.decs.act.gov.au

http://www.des.min-edu.pt

http://teachers.web.cern.ch/teachers/materials/syllabus.htm

http://www.inca.org.uk 